\title{
Visual exploratory behavior in the pigeon
}

\author{
JEANNE M. STAHL, * ROBERT A. O'BRIEN \\ Indiana University-Purdue University at Indianapolis \\ Indianapolis, Ind. 46202 \\ and \\ PETER V. HANFORD \\ Institute of Psychiatric Research \\ Indiana University Medical Center, Indianapolis, Ind. 46202
}

Pigeons were tested in an experiment designed to examine the reinforcing potential of visual stimuli after being placed in an isolation chamber. Results indicated that visual access to the room in which the pigeon colony was housed served as a reinforcer under these experimental conditions.

\section{INTRODUCTION}

A number of studies have demonstrated that the opportunity for visual exploration can serve as a reinforcer for higher animals. Butler (1953), for example, showed that monkeys which had been confined in a light-tight box would perform a task to gain visual access to the room in which the box was located. While these studies have demonstrated the motivation for visual exploration in higher animals, little work has been done on the need for visual exploration in birds. Since birds rely heavily on the visual sense for information, it seems logical that the opportunity to visually explore should serve as a reinforcer. The present study was designed to see if the opportunity for visual exploration would serve as a reinforcer for the pigeon.

\section{MÉTHOD \\ Subjects}

Two white Carneaux pigeons of undetermined age were used in this study. S $92 \mathrm{~W}$ had a history of keypecking for grain in an experiment lasting approximately 6 months. S $94 \mathrm{Y}$ was a naive bird which had been shaped to keypeck for this study. Both Ss had been housed in the colony room in which the study took place prior to the experiment.

\section{Apparatus}

The test chamber was made of plywood and measured $15 \times 15 \times 16$ in. The walls and ceiling were painted black, and the floor was a raised wire screen. A 6-W ac lamp provided continuous interior illumination, and air was circulated through the box by a blower fan. Air holes through which the air was circulated were angled to prevent the bird from looking outside the box. A standard pigeon key was placed $10 \mathrm{in}$. from the screen floor. A Burke and James 3-in.-diam electrically operated shutter was located 3 in. from the key and at the same height from the floor as the key.

The chamber was stationed in a windowless room in which the Es had approximately 100 other birds quartered. The chamber was located so that the shutter opened toward the colony, which was approximately $10 \mathrm{ft}$ away.

The operation of the shutter and recording of responses were carried out with standard operant programming and recording

*Presently at Department of Psychology, Georgia State University. equipment. Keypecks were recorded on both counters and a Gerbrands cumulative recorder.

\section{Procedure}

Each S remained in the test chamber for $24 \mathrm{~h}$ each day over the course of the experiment. The grain and water were replenished daily around 12:00 noon, which required the lid of the box to be raised for several minutes. Both Ss had continuous access to food and water throughout the experiment. No attempt was made to mask noises occurring in the room.

Each keypeck resulted in the shutter opening for $10 \mathrm{sec}$ (CRF). When the shutter was open, pecks had no effect on the duration of the shutter opening. Since both Ss responded during this CRF condition, two control procedures were programmed. The first procedure was to determine if the operation of the shutter was reinforcing keypecks. The shutter was disconnected (extinction) so that keypecks had no effect on the shutter. During this condition, responses continued to be recorded. Following this condition, the birds were returned to the CRF baseline. The second procedure was programmed to determine if the shutter opening could account for the responding. In this condition the box was rotated 180 deg so that the shutter faced an unpatterned beige wall approximately 3 in. away. The CRF schedule was maintained throughout this period. Following this condition, the box was rotated $180 \mathrm{deg}$ back to facing the colony again. The order and number of days each condition was imposed on each $\mathrm{S}$ is presented in Table 1.

\section{RESULTS AND DISCUSSION}

Figure 1 presents the daily responding for each bird over all the conditions of the experiment. The line with the open circles indicates the total responding for the 24-h period; the closed circles show the responding during the time each day that the lights in the colony room were turned out, 7:30 p.m. to 6:45 a.m. each day.

$S 92 \mathrm{~W}$ responded at an initial low level the first day, but responding increased each day, reaching a peak on the seventh day. During the remainder of the initial CRF condition, responding showed marked daily fluctuations but no consistent upward or downward trends. As this was the first bird run under these conditions, the initial CRF baseline was continued for 21 days, until we were certain that the phenomenon was valid. During extinction and when the shutter was turned toward the wall, responses dropped rapidly to near zero. Responses during the lights-out time were consistently at very low levels. Since the shutter did not open during extinction, responses during the lights-out time were not recorded separately. When the CRF baseline was reinstated following each of these conditions, responding rose rapidly but not to the same level as during the initial CRF baseline.

S 94Y, on the other hand, showed a markedly different initial baseline. Starting with a high rate of responding the first day, the number of responses dropped markedly over the next 4 days. This initial performance may reflect his recent history of being reinforced with grain for keypecking. Since this bird had 

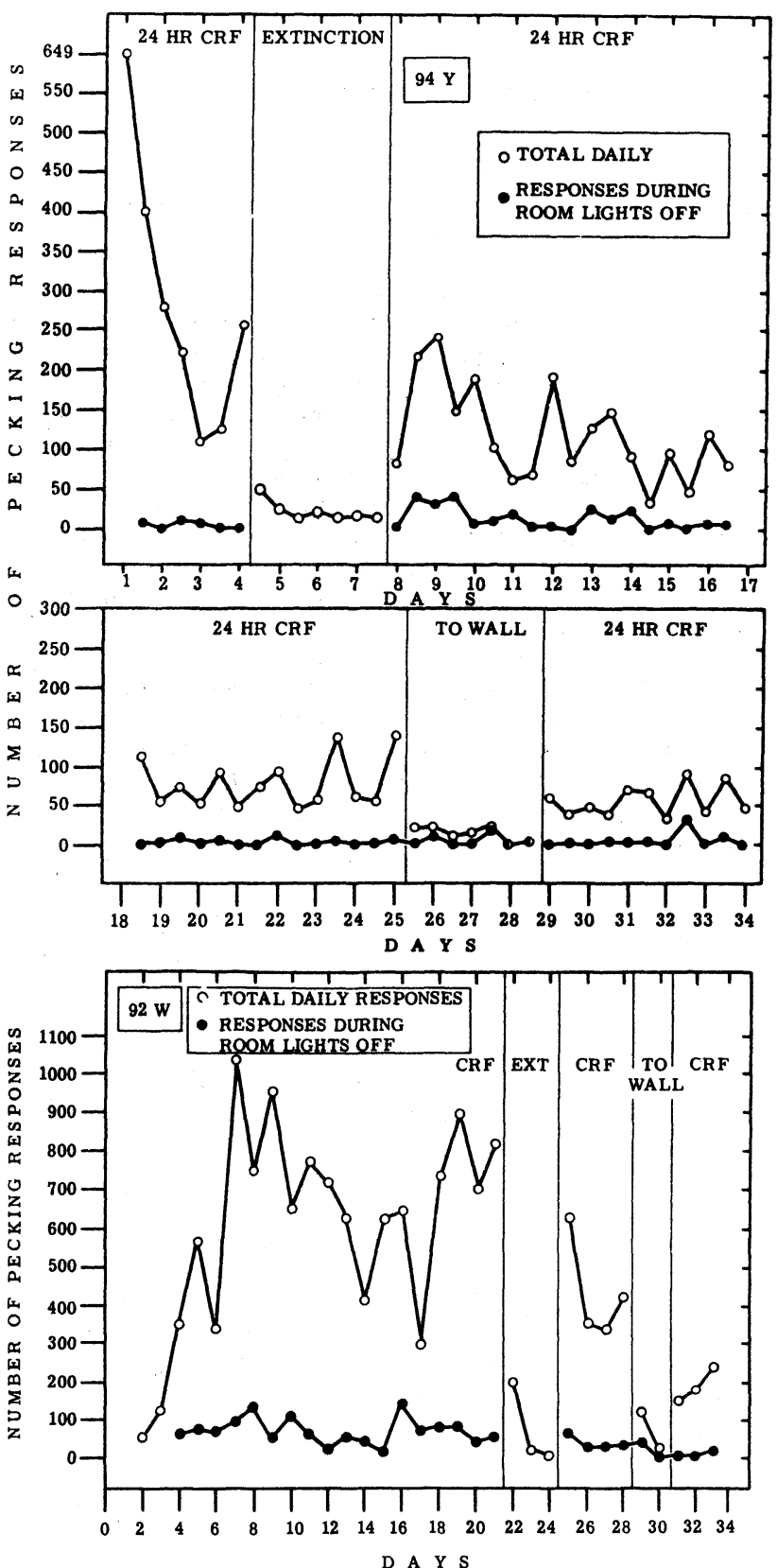

Fig. 1. Total number of daily responses during lights on or off over all the conditions of the experiment for each of the two birds used. Open circles represent the total daily responses; the closed circles represent the responses made during the lights-out condition.
Table 1

\begin{tabular}{lcr}
\hline \multirow{2}{*}{$\begin{array}{c}\text { Experimental } \\
\text { Conditions }\end{array}$} & \multicolumn{2}{c}{ Number of Days } \\
\cline { 2 - 3 } \cline { 3 - 3 } CRF & $92 \mathrm{~W}$ & $94 \mathrm{Y}$ \\
Extinction & 21 & 7 \\
CRF & 3 & 7 \\
Shutter Toward Wall & 4 & 32 \\
CRF & 2 & 7 \\
\hline
\end{tabular}

a recent history of pecking for grain, when it was apparent that the behavior was not going to extinguish, extinction was programmed, with the anticipation that the data following extinction would be a more valid indication of the reinforcing value of the visual stimuli. The remainder of 94Y's data is similar to that of $92 \mathrm{~W}$ in showing responding during CRF baselines and almost no responding during extinction or during the time when the shutter faced the wall. Responding during the lights-out period, like that of $92 \mathrm{~W}$, remained at a low level throughout the experiment.

The data of both of these Ss strongly indicates that for pigeons, as for higher animals, the opportunity to visually explore their environment when confined in a visually restricted space serves as a reinforcer.

\section{REFERENCES}

Butler, R. A. Discrimination learning by Rhesus monkeys to visual-exploration motivation. Journal of Comparative \& Physiological Psychology, 1953, 46, 95-98.

(Received for publication September 13, 1972.) 